\title{
THE STUDY OF THE LEVELS OF METALLOPROTEINASES, CYTOKINES AND LYMPHOCYTE ACTIVATION MARKERS IN SEMINAL PLASMA OF MEN, DEPENDING ON FERTILITY
}

\author{
Serhii Tsiporenko \\ Department of Family Medicine and Outpatient Clinical Care \\ Shupyk National Medical Academy of Postgraduate Education \\ 9 Dorogozhytska str., Kyiv, Ukraine, 04112 \\ tsiporenko@ukr.net \\ Larysa Matyucha \\ Department of Family Medicine and Outpatient Clinical Care \\ Shupyk National Medical Academy of Postgraduate Education \\ 9 Dorogozhytska str., Kyiv, Ukraine, 04112
}

\begin{abstract}
The study of the concentration of metalloproteinases, pro- and anti-inflammatory cytokines, lymphocyte activation markers in seminal plasma of men with oligosymptomatic forms of chronic inflammation of the urogenital tract (CIUT), depending on the fertility rate are presented in the article.

Quantitative characteristics in male sperm with different forms of pathospermia were studied for matrix metalloproteinases (MMP)-2 and MMP-9 and their inhibitors - tissue inhibitors of metalloproteinases (TIMP)-1 and TIMP-2. It was shown, that during chronic inflammation of the urogenital tract of men are shifting levels of cytokine profile, reducing the concentration of metalloproteinase-2, chemokines - fractalkine and regulated by activation, expression and secretion of normal T-cells (RANTES), sharp increase in IL-8, MCP-1 and elevation of the CD25+/CD95+, indicating that the disturbance of apoptosis of pathological forms generative cells and their accumulation in the sperm.

The ratio of immunological indices IL-2/IL-4, IL-10/IL-12 was calculated and a significant increase in the IL-10/IL-12 index was noted in the group of individuals with elevated levels of hypercapitated form of sperm, and a reduced proportion of this ratio was observed in the microsomatic morphology of sperm. Prolonged inflammation in the genital area accompanied by depletion of the local immune system, resulting in the development of infertility.

Immunocorrection therapy for men with CIUT should take into account the peculiarities of changes in local immunity and be differentiated depending on the prevalence of certain pathological forms of sperm and changes in the cytokine profile of the seminal plasma.
\end{abstract}

Keywords: male infertility, sperm, seminal plasma, metalloproteinase, cytokine profile, markers of lymphocyte activation.

\section{Introduction}

One of the main directions of modern scientific research is the study of proteolysis as a special form of biological regulation. Proteolysis is constantly occurring in living organisms and in the environment under the influence of microorganisms, resulting in a variety of biologically active substances - enzymes, hormones, peptides, amino acids, etc. Proteolytic enzymes that have high biological activity are involved into the functioning of various organs and systems of the body and in the regulation of biological processes. They not only carry out non-specific decomposition of protein molecules, but also control the functions and systems of the organism, which is realized in the reactions of general and limited proteolysis. According to modern notions, protease enzymes support the balance between death and cell degradation and their recovery, they participate in cellular mechanisms of proteasome degradation [1]. The proteolytic processes are necessary for the normal functioning of the organism. Violations of the mechanisms of biological regulation can cause serious diseases: arthritis, multiple sclerosis, cancerous tumors, and others. Proteolytic enzymes play an important role in metastasis in the passage of malignant cells through the membrane, their migration and invasion into the extracellular matrix. In these processes, 4 classes of 
proteolytic enzymes - matrix metalloproteinases, cysteine and serine proteinases, as well as protein kinase aspartate of cathepsin D - participate [2, 3]. Matrix metalloproteinases (MMP) - the family of extracellular zinc-containing proteinases. Today about 30 MMPs are known, their role in the processes of morphogenesis, apoptosis, remodeling and resorption of tissues continues to be studied $[4,5]$. There are five types of MMP: collagenase (MMP-1, -8 and -13 ), glutathione (MMP-2 and -9), stromelysin (MMP-3, -10, -11), elastase (MMP-7, -12) and the membrane type (MT-MMP, MMP-14, -15, -16 and -17) [6, 7].

MMPs are secreted as well as inflammatory and stromal cells in response to exogenous stimuli and proinflammatory cytokines: tumor necrosis factor (TNF)- $\alpha$, interleukin (IL)-1 $\beta$. Such cytokines, such as interferon (IFN)- $\gamma$, IL-4 and IL-10, decrease the secretion of MMP [8, 9].

The substrate for MMP-2 and MMP-9 is collagen I, IV, V, VII and X types, elastin, fibronectin, IL-1 $\beta$, IL-2, IL-8, IL-15, transforming growth factor (TGF)- $\beta$, chemokines, INF- $\beta$, soluble forms of receptors for a number of interleukins, etc. The works of scientists has determined the effect of MMP-3, MMP-8, MMP-13, MMP-14, MMP-28 on the level of several chemokines: fractalkine, IL-8, regulated by activation, expression and secretion of normal T cells (RANTES) $[10,11]$. Consequently, metalloproteinases are involved into the development of the inflammatory process $[12,13]$. Protective functions for MMP-9 were revealed in the suppression of lymphoproliferation and dampening of systemic autoimmunity, cautioning against the long-term use of MMP inhibitors in autoimmune lymphoproliferative syndrome [14]. MMP2 and MMP9 lay a key role in regulating T-cell activation [15]. MMP activity is regulated by tissue inhibitors of metalloproteinases (TIMP) $[16,17]$. The role of MMP in the functioning of the male reproductive system and in the fertilizing ability of sperm [18] was investigated. The raised levels of MMP-2 and MMP-9 in the secretion of prostate and testicles in men with prostate hyperplasia were demonstrated [19]. Quantitative characteristics in male sperm with different forms of pathospermia were studied for MMP-2 and MMP-9 and their inhibitors TIMP-1 and TIMP-2 [20]. It is believed that TIMP-1 is specific for MMP-9, and TIMP-2 for MMP-2 [10]. It is clear that during the inflammatory process in the urogenital tract of men, the levels of cytokines and biological substances that regulate their functional activity undergo certain changes. In men with chronic urogenital infection, a significant increase in the concentration of a number of cytokines - IL-1 $\beta$, IL-5, IL-6, IL-13, IL-15, IL-17, IL-23, INF- $\alpha$, monocytic chemotactic factor (MCP) and to a lesser extent - IL-2, IL-10, IL-12, IL-18, TNF- $\alpha$, INF- $\gamma$ [21]. The elevated levels of these inflammatory mediators indicate the involvement of immune factors to protect the male genital tract. These changes are more important in the development of complications, in particular, infertility. The study of the peculiarities of the interaction of cytokines and metalloproteinases during inflammation in male genitals, obviously, will have not only diagnostic and therapeutic value, but may also address the issue of increasing the fertilizing potential [11].

\section{Aim of the research}

The objective of this study was to investigate the pro- and antiinflammatory cytokines in the seminal plasma of men with chronic inflammation of the urogenital tract (CIUT), CD4+CD25+, CD4+HLA-DR4+ and CD4+CD95+ lymphocytes activation markers, MMP-2 metalloproteinase, MMP-9 and their inhibitors TIMP-1, TIMP-2 depending on fertility.

\section{Materials and methods}

The research was conducted on the basis of the Department of Family Medicine and Outpatient Clinical Care and the Research Laboratory of the National Medical Academy of Postgraduate Education named after P. Shupik from 2013 to 2016.

Under our supervision were 69 patients with olygosymptomatic forms of chronic inflammation of the urogenital tract (CIUT) aged from 24 to 40 years. All subjects were divided into two groups: the first (35 people) - infertile men and the second (34 people) - fertile men. All patients were examined clinically, including examination and palpation of the penis, scrotum and prostate gland, and carefully collected anamnesis. All patients gave semen for analysis. The ejaculation should not occur within 4-5 days on the eve of the delivery. Semen analysis was performed half an 
hour after ejaculation and in accordance with WHO guidelines. Considered the concentration of sperm, $\mathrm{pH}$ of semen, the content of leukocytes and their populations (granulocytes, macrophages, lymphocytes). Patients with leucospermia were not included in the study. To determine the morphology staining for Papanicolaou was used.

The levels of the following cytokines in serum and seminal plasma were studied by immunoassay in laboratory equipment of Sanofi diagnostic Pasteur (France) using ProCon (Protein Contour, SPb) certified test systems in Ukraine: IL-1 $\beta$, IL-2 , IL-4, IL-6, IL-10, FNP- $\alpha$. The concentration of IFN- $\gamma$ was studied using the Ukrainian-certified test systems of the diagnostic systems (RF - Nizhny Novgorod). IL-8 and MCP-1 cytokine levels were tested in serum of blood and serum from semen by an immuno-enzymatic method using the IFA-BEST test system of LLC Vector-Best, Saint-Petersburg, level RANTES (regulated by activation, expression and secretion of normal T cells) and fractalkine test systems of RayBiotech, Inc., USA. The concentrations of IL-12 and IL-18 cytokines in serum and seminal plasma were determined by immunoassay using the STAT-FAX-303 PLUS analyzer (USA) at a wavelength of $492 \mathrm{~nm}$. To determine the level of lymphocytes that expressed on their surface receptors for functional activation of CD4+CD25+, CD4+CD95+, CD4 + HLA-DR4 + (TRAIL receptor 1) cells, was used an erythrocytic diagnosticum with monoclonal antibodies produced by the MedBioProject (RF) - Moscow) The ratio of immunological indices IL-2/IL-4, IL-10/IL-12 and CD25+/CD95+ was calculated.

The levels of MMP-2, MMP-9, TIMP-1 and TIMP-2 were measured in serum from sperm by the immuno-enzymatic method using the Ameters int. (United Kingdom) Biotrak test system.

Control parameters of concentrations of all of the above-mentioned cytokines were obtained during the study of 24 fertile men without clinical signs of the disease, similar in composition according to age.

Statistical analysis was performed on a personal computer using the MedStat program package [22]. At the same time criterion $\chi^{2}$ was used for checking the indicators for normal distribution. The median was calculated, $25 \%$ quartile, $75 \%$ quartile, confidence intervals. To compare the indicators, the criterion $\chi^{2}$, the two-sided critical region, was used. To analyze the presence and the strength of the relationship, the Kendal correlation coefficient $\tau$ was calculated.

\section{Results}

The study of levels of metalloproteinases MMP-2, MMP-9 and their inhibitors TIMP-1, TIMP-2 in serum of male sperm with CIUT showed that the level of MMP-2 was significantly lowered compared to control values. However, the MMP-2 in the group of infertility men declined more significantly - the difference of 2.9, in the group of fertile men the multiplicity of the difference was 1.4. The levels of MMP-9, TIMP-1 and TIMP-2 did not differ from the normative (Table 1).

\section{Table 1}

Indicators of levels of metalloproteinases and their serum plasma inhibitors in men with CIUT (Me $\pm \mathrm{m}$ [95\% confidence interval])

\begin{tabular}{cccc}
\hline Indexes & Norm & Infertile men & Fertile men \\
\hline MMP-2, ng/ml & $1646.4 \pm 124.8$ & $576.489 .3 \pm * * *$ & $1134.478 .6 \pm * *$ \\
& {$[1351.2 ; 1967.4]$} & {$[351.3 ; 767.6]$} & {$[993.7 ; 1349.8]$} \\
MMP-9, ng/ml & $47.49 .7 \pm$ & $44.98 .5 \pm$ & $45.57 .9 \pm$ \\
& {$[21.2 ; 77.4]$} & {$[29.1 ; 67.7]$} & {$[31.8 ; 68.5]$} \\
TIMP-1,ng/ml & $23478.3675 .4 \pm$ & $27547.6704 .7 \pm$ & $24163.6694 .1 \pm$ \\
& {$[21751.2 ; 24867.4]$} & {$[25424.5 ; 28667.6]$} & {$[21974.3 ; 2589.7]$} \\
TIMP-2, ng/ml & $4538.2358 .5 \pm$ & $4794.5289 .9 \pm$ & $4635.9311 .5 \pm$
\end{tabular}

Note: the reliability of the difference between the indicators of the group and the indicators taken at the norm at values $P: *-<0,05$, $* *_{-}<0,01, * * *_{-}<0,001$ 
The results of the study of the cytokine profile indicate that in the examined patients with infertility there is a significant increase in the concentration of IL- 8 in the seminal plasma $(215.5 \pm$ $\pm 7.8 \mathrm{pg} / \mathrm{ml}, \mathrm{p}<0.01)$ and the monocytic chemotactic factor MCP $(926.4 \pm 30.2 \mathrm{pg} / \mathrm{ml}, \mathrm{p}<0.001)$, in the group of fertile men the levels of these cytokines also increased $(85.5 \pm 5.7 \mathrm{pg} / \mathrm{ml}, \mathrm{p}<0.01$ and $185.2 \pm 12.5 \mathrm{pg} / \mathrm{ml}, \mathrm{p}<0.001$, respectively), but the multiplicity of the difference was significantly lower compared to infertile men (Table 2). So for IL-8, the multiplicity of difference in the group of infertility and in the group of fertile men was 6.0 and 2.4 respectively, for MCP -11.2 and 2.2.

Table 2

Immunological parameters of male sperm serum with CIUT (Me $\pm \mathrm{m}[95 \%$ confidence interval])

\begin{tabular}{|c|c|c|c|}
\hline Indexes & Norm & Infertile men & Fertile men \\
\hline $\mathrm{IL}-1 \beta, \mathrm{pg} / \mathrm{ml}$ & $\begin{array}{c}54.6 \pm 0.8 \\
{[51.2 ; 67.4]}\end{array}$ & $\begin{array}{c}5.4 \pm 0.5 * * * \\
{[5.1 ; 6.3]}\end{array}$ & $\begin{array}{l}36.4 \pm 2.1^{* *} \\
{[31.3 ; 39.8]}\end{array}$ \\
\hline $\mathrm{IL}-2, \mathrm{pg} / \mathrm{ml}$ & $\begin{array}{c}86.5 \pm 1.7 \\
{[63.4 ; 89.5]}\end{array}$ & $\begin{array}{c}14.2 \pm 1.3^{* * *} \\
{[12.5 ; 16.5]}\end{array}$ & $\begin{array}{l}47.7 \pm 5.1^{* *} \\
{[35.2 ; 64.6]}\end{array}$ \\
\hline IL-4, pg/ml & $\begin{array}{c}24.1 \pm 1.2 \\
{[23.5 ; 32.7]}\end{array}$ & $\begin{array}{c}24.1 \pm 0.5 \\
{[23.1 ; 25.6]}\end{array}$ & $\begin{array}{c}25.1 \pm 0.9 \\
{[23.1 ; 27.6]}\end{array}$ \\
\hline IL-6, pg/ml & $\begin{array}{c}34,1 \pm 1,2 \\
{[32,1 ; 36,7]}\end{array}$ & $\begin{array}{c}32,2 \pm 1,4 \\
{[30,2 ; 35,7]}\end{array}$ & $\begin{array}{c}32,0 \pm 1,3 \\
{[30,1 ; 34,5]}\end{array}$ \\
\hline IL-8, pg/ml & $\begin{array}{c}36,1 \pm 1,5 \\
{[35,4 ; 40,3]}\end{array}$ & $\begin{array}{l}215,5 \pm 7,8 * * * \\
{[197,0 ; 237,7]}\end{array}$ & $\begin{array}{c}85,5 \pm 5,7 * * \\
{[69,4 ; 107,5]}\end{array}$ \\
\hline IL-10, pg/ml & $\begin{array}{c}36,3 \pm 1,3 \\
{[32,2 ; 39,4]}\end{array}$ & $\begin{array}{c}35,1 \pm 1,3 \\
{[32,5 ; 41,5]}\end{array}$ & $\begin{array}{c}35,6 \pm 1,5 \\
{[32,4 ; 40,1]}\end{array}$ \\
\hline IL-12, pg/ml & $\begin{array}{c}13,6 \pm 1,4 \\
{[11,8 ; 15.8]}\end{array}$ & $\begin{array}{c}9.6 \pm 0.3^{*} \\
{[8.3 ; 10.2]}\end{array}$ & $\begin{array}{c}13.5 \pm 0.8 \\
{[11.5 ; 15.7]}\end{array}$ \\
\hline IL-18, pg/ml & $\begin{array}{c}28.1 \pm 0.8 \\
{[25.6 ; 30.4]}\end{array}$ & $\begin{array}{c}21.0 \pm 0.6^{* * *} \\
{[16.8 ; 22.5]}\end{array}$ & $\begin{array}{l}25.5 \pm 1.2 * \\
{[22.6 ; 27.1]}\end{array}$ \\
\hline IL-2/ IL-4 & $\begin{array}{l}3.5 \pm 0.3 \\
{[2.9 ; 5.1]}\end{array}$ & $\begin{array}{c}0.6 \pm 0.2 * * * \\
{[0.4 ; 1.7]}\end{array}$ & $\begin{array}{c}1.9 \pm 0.3 * * \\
{[1.4 ; 2.6]}\end{array}$ \\
\hline IL-10/ IL-12 & $\begin{array}{c}2.7 \pm 0.2 \\
{[2.2 ; 5.4]}\end{array}$ & $\begin{array}{c}3.7 \pm 0.32 * * \\
{[2.0 ; 6.7]}\end{array}$ & $\begin{array}{c}2.6 \pm 0.27 \\
{[2.1 ; 4.1]}\end{array}$ \\
\hline $\mathrm{MCP}, \mathrm{pg} / \mathrm{ml}$ & $\begin{array}{c}82.4 \pm 1.4 \\
{[78.8 ; 80.3]}\end{array}$ & $\begin{array}{c}926.4 \pm 30.2^{* * *} \\
{[845.1 ; 969.6]}\end{array}$ & $\begin{array}{c}185.2 \pm 12.5^{* * *} \\
{[886.0 ; 992.8]}\end{array}$ \\
\hline $\mathrm{TNF}-\alpha, \mathrm{pg} / \mathrm{ml}$ & $\begin{array}{c}12.9 \pm 0.5 \\
{[11.2 ; 15.9]}\end{array}$ & $\begin{array}{c}12.1 \pm 0.9 \\
{[11.5 ; 15.2]}\end{array}$ & $\begin{array}{c}11.9 \pm 1.0 \\
{[11.0 ; 14.7]}\end{array}$ \\
\hline RANTES, pg/ml & $\begin{array}{c}40.5 \pm 2.2 \\
{[37.6 ; 43.5]}\end{array}$ & $\begin{array}{c}12.7 \pm 1.0 * * * \\
{[9.8 ; 14.6]}\end{array}$ & $\begin{array}{l}45.8 \pm 2.3^{*} \\
{[40.1 ; 49.7]}\end{array}$ \\
\hline Fractalkine, $\mathrm{pg} / \mathrm{ml}$ & $\begin{array}{c}29.4 \pm 1.5 \\
{[26.1 ; 32.0]}\end{array}$ & $\begin{array}{c}16.3 \pm 1.3 * * * \\
{[12.9 ; 18.4]}\end{array}$ & $\begin{array}{l}87.4 \pm 8.2 * * * \\
{[73.6 ; 108.0]}\end{array}$ \\
\hline INF- $\gamma, \mathrm{pg} / \mathrm{ml}$ & $\begin{array}{l}5.3 \pm 0.2 \\
{[5.0 ; 5.7]}\end{array}$ & $\begin{array}{c}5.1 \pm 1.2 \\
{[4.3 ; 7.1]}\end{array}$ & $\begin{array}{l}5.0 \pm 0.8 \\
{[3.5 ; 7.3]}\end{array}$ \\
\hline $\mathrm{CD} 4+\mathrm{CD} 25+, \%$ & $\begin{array}{c}10.7 \pm 1.5 \\
{[9.3 ; 14.4]}\end{array}$ & $\begin{array}{l}16.3 \pm 1.4^{* *} \\
{[12.5 ; 19.6]}\end{array}$ & $\begin{array}{c}12.4 \pm 1.3 \\
{[10.2 ; 15.6]}\end{array}$ \\
\hline $\mathrm{CD} 4+\mathrm{CD} 95+, \%$ & $\begin{array}{c}11.8 \pm 1.2 \\
{[8.1 ; 14.0]}\end{array}$ & $\begin{array}{l}17.9 \pm 1.3^{* *} \\
{[10.3 ; 21.1]}\end{array}$ & $\begin{array}{c}24.2 \pm 1.5^{* * *} \\
{[20.1 ; 28.6]}\end{array}$ \\
\hline CD4+HLA-DR4+, \% & $\begin{array}{l}1.2 \pm 0.2 \\
{[0.9 ; 1.4]}\end{array}$ & $\begin{array}{l}1.8 \pm \cdot .2 * \\
{[1.4 ; 1.9]}\end{array}$ & $\begin{array}{l}1.3 \pm \cdot .2 \\
{[0.9 ; 1.7]}\end{array}$ \\
\hline CD25+/CD95+ & $\begin{array}{c}0.900 .14 \pm \\
{[0.80 ; 1.12]}\end{array}$ & $\begin{array}{l}0.970 .12 \pm * \\
{[0.96 ; 1.22]}\end{array}$ & $\begin{array}{l}0.510 .11 \pm * \\
{[0.39 ; 0.65]}\end{array}$ \\
\hline
\end{tabular}

Note: the reliability of the difference between the indicators of the group of infertility men and the rates taken for the norm at values $P: *_{-}<0,05 ; * *_{-}<0,01 ; * * *_{-}<0,001$ 
At the same time, in infertile men observed a significant decrease in the serum plasma concentrations of IL- $1 \beta(5.4 \pm 0.5 \mathrm{pg} / \mathrm{ml}, \mathrm{p}<0.01)$, IL-2 $(14.2 \pm 1.3 \mathrm{pg} / \mathrm{ml}, \mathrm{p}<0.01)$, IL-12 $(9.6 \pm 0.3 \mathrm{pg} / \mathrm{ml}$, $\mathrm{p}<0.01)$, IL-18 $(21.0 \pm 0.6 \mathrm{pg} / \mathrm{ml}, \mathrm{p}<0.01)$. In the group of fertile men, the abovementioned cytokines also decreased, but less importantly than in infertile men. The concentrations of TNF- $\alpha$, IL-4, IL-6, IL-10, IFN- $\gamma$ in the seminal plasma of both groups of men did not exceed the corresponding mean concentrations of healthy men. Moreover, the levels of concentration of all of the abovementioned cytokines in the peripheral blood of patients with CIUT varied within normal limits. Interestingly, the study of the IL-10/IL-12 ratio was quite interesting. The literature indicates that a decrease in the IL-10/IL-12 ratio is a key factor in suppressing the effectiveness of local immune defense in the lower sections of the urogenital tract, inhibition of cellular mediated immune response, and the development of immunosuppression [23, 24]. In our study, there were diverse shifts in this ratio of infertility men. A significant increase in the IL-10/IL-12 index was noted in the group of individuals with elevated levels of hypercapitated form of sperm, and a reduced proportion of this ratio was observed in the microsomatic morphology of sperm. The obtained data emphasize the importance of microenvironment in the process of maturation of gametes. In the group of infertile men, the concentration of RANTES was significantly lower than normal $(12.7 \pm 1.0 \mathrm{pg} / \mathrm{ml}, \mathrm{p}<0.05)$. And the multiplicity of the difference on average was 3.2 times. However, in part of the patients of the infertile group (14 people) the difference in frequency was 6.3 times (mean $6.4 \pm 0.8 \mathrm{pg} / \mathrm{ml}$, $\mathrm{p}<0.001)$. Morphometry of the sperm in this group of patients showed hypercapitated morphotype of sperm $(\tau=-0,86, p=0,4)$. The level of fractakline in the serum of semen of infertile patients significantly decreased $(16.3 \pm 1.3 \mathrm{pg} / \mathrm{ml}, \mathrm{p}<0.001)$. In the group of fertile men, the levels of RANTES and fractakline, on the contrary, increased $(45.8 \pm 2.3 \mathrm{~g} / \mathrm{ml}, \mathrm{p}<0.05$ and $87.4 \pm 8.2 \mathrm{pg} / \mathrm{ml}, \mathrm{p}<0.001$, respectively).

In patients with CIUT, which was complicated by infertility, there was a marked increase in CD4+CD25+ levels in sperm, both in relative and absolute values and was $16.3 \pm 1.4 \%, \mathrm{p}<0.01$ $(10.7 \pm 1.5 \%$ in the control group), $(\mathrm{p}<0.05)$, indicating an increased activity against infectious defense. At the same time, the mean value of CD4+CD25+ in semen was not changed in fertile men. The level of lymphocytes in the sperm of the infertile men with CD4+CD95+ expression was elevated in compare to the control group in both relative and absolute values and was $17.9 \pm 1.3 \%$, $\mathrm{p}<0.01$ (11.8 $\pm 1.2 \%$ in the control group). The frequency difference was 1.5 times. At the same time, some of the patients in this group (12 people), the level of CD4+CD95+ in the sperm, on the contrary, decreased with respect to control, and the average value for this part of the patients was $9.0 \pm 1.1 \%,(\mathrm{p}<0.01)$, which was less than 1,3 times the adopted norm. Decreased immunocompetent cells ready to enter the process of apoptosis can lead to imbalances in the immune system. About the activation of anti-infective protection is the tendency to increase the absolute level of cells with expression of CD4+HLA-DR4+ in this group of patients. In view of the literature data [25], we calculated the ratio of CD25+/CD95+. The study showed that there is a positive correlation between the increased value of the proportion of $\mathrm{CD} 25+/ \mathrm{CD} 95+$ and the presence of hypercapitated forms of sperm. At the same time, an increase in this index was observed in the group of infertile men. A significant decrease in the proportion of CD25+/CD95+ was observed in a group of infertile men, whose spermometry has established the predominance of normosomatic forms of sperm. The obtained data, in our opinion, testify to the toxic effect of activated lymphocytes in the sperm against the suppression of the processes of apoptosis.

\section{Discussion}

The results of our study showed that the development of such a complication in men, as infertility on the background of chronic inflammation of the urogenital tract is accompanied not only by the shift of microenvironment, but also by pathomorphological changes in the generative cells. The literature notes that MMP-2 inactivates a number of chemokines - fractakline, RANTES and proinflammatory cytokines - IL-1 $\beta$, TNF- $\beta$ [26]. The IL-8 protein under the influence of MMP-9, on the other hand, leads to increased activity of this cytokine [11]. MMP-9 by inactivating INF- $\gamma$ can lead to prolonged inflammation [7]. Inflammation is usually characterized by elevated levels of metalloproteinases [9], however, the male examination from CIUT indicates, on the contrary, 
a decrease in MMP-2 levels and a normal level of MMP-9 in serum, along with lower concentrations of proinflammatory cytokines IL-1 $\beta$, IL-2, IL-12, IL-18, which may indicate an exhaustion of the local immune system, despite normal immunological parameters in systemic circulation. The altered parameters of the cytokine profile in the urogenital tract obviously adversely affect the processes of maturation, which results in the prevalence of pathological forms of sperm in the group of infertile men. Thus, the determination of the lower concentration of MMP-2 in serum can be a negative predictor of the development of infertility.

\section{Conclusions}

1. During the chronic inflammation in the urogenital tract, men undergo changes in pro- and anti-inflammatory cytokine levels, decreased concentrations of MMP-2, chemokines-fractalkine and RANTES, a sharp increase in IL-8, MCP-1 and an increase in the CD25+/CD95+ index, indicating on violation of the processes of apoptosis of pathological forms of the generative cells, which leads to their accumulation in the semen.

2. Long inflammatory process in the genital organs is accompanied by exhaustion of the local immune system, resulting in the development of infertility.

3. Immunocorrection therapy for men with CIUT should take into account the peculiarities of changes in local immunity and be differentiated depending on the prevalence of certain pathological forms of sperm and changes in the cytokine profile of the seminal plasma.

\section{References}

[1] Orlova, L., Pyetrov, S. (2011). Aktyvnist metaloproteinazy matryksu (MMP-2) I. Katepsynopodibnoyi proteyinazy D u riznych vydiv zmiy. Visnyk Lvivskogo Universytetu, 55, 34-38.

[2] Syed, R., Farukh, R., Shaista, R., Akbar, M., Shajrul, A. (2012). Role of proteases in cancer: A review. Biotechnology and Molecular Biology Reviews, 7 (4), 90-101. doi: 10.5897/bmbr11.027

[3] Radisky, E. S., Radisky, D. C. (2010). Matrix Metalloproteinase-Induced Epithelial-Mesenchymal Transition in Breast Cancer. Journal of Mammary Gland Biology and Neoplasia, 15 (2), 201-212. doi: 10.1007/s10911-010-9177-x

[4] Jablonska-Trypuc, A., Matejczyk, M., Rosochacki, S. (2016). Matrix metalloproteinases (MMPs), the main extracellular matrix (ECM) enzymes in collagen degradation, as a target for anticancer drugs. Journal of Enzyme Inhibition and Medicinal Chemistry, 31, 177-183. doi: 10.3109/ 14756366.2016.1161620

[5] Lu, P., Takai, K., Weaver, V. M., Werb, Z. (2011). Extracellular Matrix Degradation and Remodeling in Development and Disease. Cold Spring Harbor Perspectives in Biology, 3 (12), a005058. doi: 10.1101/ cshperspect.a005058

[6] Brilha, S., Wysoczanski, R., Whittington, A. M., Friedland, J. S., Porter, J. C. (2017). Monocyte Adhesion, Migration, and Extracellular Matrix Breakdown Are Regulated by Integrin $\alpha \mathrm{V} \beta 3$ inMycobacterium tuberculosisInfection. The Journal of Immunology, 199 (3), 982-991. doi: 10.4049/jimmunol.1700128

[7] Chou, C. H., Teng, C.-M., Tzen, K.-Y., Chang, Y.-C., Chen, J.-H., Cheng, J. C.-H. (2011). MMP-9 from sublethally irradiated tumor promotes Lewis lung carcinoma cell invasiveness and pulmonary metastasis. Oncogene, 31 (4), 458-468. doi: 10.1038/onc.2011.240

[8] Song, J., Wu, C., Korpos, E., Zhang, X., Agrawal, S. M., Wang, Y. et. al. (2015). Focal MMP-2 and MMP-9 Activity at the Blood-Brain Barrier Promotes Chemokine-Induced Leukocyte Migration. Cell Reports, 10 (7), 1040-1054. doi: 10.1016/j.celrep.2015.01.037

[9] Newby, A. C., George, S. J., Ismail, Y., Johnson, J. L., Sala-Newby, G. B., Thomas, A. C. (2009). Vulnerable atherosclerotic plaque metalloproteinases and foam cell phenotypes. Thrombosis and Haemostasis, 101 (6), 1006-1011. doi: 10.1160/th08-07-0469

[10] Agere, S. A., Akhtar, N., Watson, J. M., Ahmed, S. (2017). RANTES/CCL5 induces collagen degradation by activating MMP-1 and MMP-13 expression in human rheumatoid arthritis synovial fibroblasts. Frontiers in Immunology, 8, 1341. doi: 10.3389/fimmu.2017.01341

[11] Gounko, N. V., Martens, E., Opdenakker, G., Rybakin, V. (2016). Thymocyte development in the absence of matrix metalloproteinase-9/gelatinase B. Scientific Reports, 6 (1). doi: 10.1038/srep29852 
[12] Verma, R. P., Hansch, C. (2007). Matrix metalloproteinases (MMPs): Chemical-biological functions and (Q)SARs. Bioorganic \& Medicinal Chemistry, 15 (6), 2223-2268. doi: 10.1016/ j.bmc.2007.01.011

[13] Fanjul-Fernandez, M., Folgueras, A. R., Cabrera, S., Lopez-Otín, C. (2010). Matrix metalloproteinases: Evolution, gene regulation and functional analysis in mouse models. Biochimica et Biophysica Acta (BBA) - Molecular Cell Research, 1803 (1), 3-19. doi: 10.1016/j.bbamcr.2009.07.004

[14] Cauwe, B., Martens, E., Sagaert, X., Dillen, C., Geurts, N., Li, S. et. al. (2011). Deficiency of gelatinase B/MMP-9 aggravates lpr-induced lymphoproliferation and lupus-like systemic autoimmune disease. Journal of Autoimmunity, 36 (3-4), 239-252. doi: 10.1016/j.jaut.2011.02.002

[15] Benson, H. L., Mobashery, S., Chang, M., Kheradmand, F., Hong, J. S., Smith, G. N. et. al. (2011). Endogenous Matrix Metalloproteinases 2 and 9 Regulate Activation of CD4+and CD8+T cells. American Journal of Respiratory Cell and Molecular Biology, 44 (5), 700-708. doi: 10.1165/rcmb. 2010-0125oc

[16] Sato, W., Tomita, A., Ichikawa, D., Lin, Y., Kishida, H., Miyake, S. et. al. (2012). CCR2+ CCR5+ T Cells Produce Matrix Metalloproteinase-9 and Osteopontin in the Pathogenesis of Multiple Sclerosis. The Journal of Immunology, 189 (10), 5057-5065. doi: 10.4049/jimmunol.1202026

[17] Pagemccaw, A. (2008). Remodeling the model organism: Matrix metalloproteinase functions in invertebrates. Seminars in Cell \& Developmental Biology, 19 (1), 14-23. doi: 10.1016/j.semcdb.2007.06.004

[18] Mohagheghi, S., Khodadadi, I., Karami, M., Amiri, I., Tavilani, H. (2018). Gene polymorphism of Matrix Metalloproteinase 9 in asthenozoospermic male subjects. International Journal of Fertility \& Sterility, 11 (4), 247-252.

[19] Moroz, A., Delella, F. K., Almeida, R., Lacorte, L. M., Favaro, W. J., Deffune, E., Felisbino, S. L. (2013). Finasteride Inhibits Human Prostate Cancer Cell Invasion through MMP2 and MMP9 Downregulation. PLoS ONE, 8 (12), e84757. doi: 10.1371/journal.pone.0084757

[20] Ayvazova, N. P., Rilcheva, V. S., Konova, E. I., Roussev, R. G., Rashev, P. I. (2016). Original Article. Matrix Metalloproteinase Mmp-2 and Mmp-9 Activities in Seminal Plasma. Journal of Biomedical and Clinical Research, 9 (2). doi: 10.1515/jbcr-2016-0016

[21] Fraczek, M., Kurpisz, M. (2015). Cytokines in the male reproductive tract and their role in infertility disorders. Journal of Reproductive Immunology, 108, 98-104. doi: 10.1016/j.jri.2015.02.001

[22] Lyah, Yu. Ye., Guryanov, V. G. (2004). Osnovy computernoy biostatistiki: analiz informatsii v biologii, meditsinye i farmatsii statistichyeskim pakyetom MedStat. Donetsk, 212.

[23] Hohn, A., Weber, D., Jung, T., Ott, C., Hugo, M., Kochlik, B. et. al. (2017). Happily (n)ever after: Aging in the context of oxidative stress, proteostasis loss and cellular senescence. Redox Biology, 11, 482-501. doi: 10.1016/j.redox.2016.12.001

[24] Kelly, R. W., Carr, G. G., Critchley, H. O. (1997). A cytokine switch induced by human seminal plasma: an immune modulation with implications for sexually transmitted disease. Human Reproduction, 12 (4), 677-681. doi: 10.1093/humrep/12.4.677

[25] Shuganov, E. G., Raspopina, N. A., Salmasi, Z. M. (2016). Clinical and immunological correlations in chronic obstructive pulmonary disease and bronchial asthma. Almanac of Clinical Medicine, 35, 54-59. doi: 10.18786/2072-0505-2014-35-54-59

[26] Loetscher, P., Clark-Lewis, I. (2001). Agonistic and antagonistic activities of chemokines. Journal of Leukocyte Biology, 69, 881-884. 